\title{
ELECTRICAL SPLINTING OF THE KNEE IN PARAPLEGIA
}

\author{
By G. S. Brindley, M.D., F.R.C.P., C. E. Polkey, M.D., F.R.C.S. and \\ D. N. Rushton, M.D., M.R.C.P. \\ M.R.C. Neurological Prostheses Unit and Neurosurgical Unit, The Maudsley Hospital, \\ London, England
}

Abstract. Two men with $\mathrm{T}_{7}$ and $\mathrm{T}_{12}$ complete traumatic lesions have received implants to stimulate the femoral nerves and (in the $\mathrm{T}_{7}$ case) the inferior and superior gluteal nerves. By using these continuously at 13 pulses/sec they can stand and walk, as other paraplegics do with calipers. Regular stimulation at I I or I3 pulses/sec greatly increases the force exerted by the quadriceps femoris muscles and their resistance to fatigue, and this improvement is not lost during 2 months without stimulation.

Key words: Paraplegia; Femoral nerve stimulator; Implant; Muscle fatigue.

\section{Introduction}

Some paraplegic patients learn to stand and walk, after a fashion, with the aid of crutches and knee calipers. The legs are used as pillars, and (in the case of complete paraplegia) are brought forward together, rather than alternately. This walking technique is clumsy and difficult to learn; but it is also tedious to prepare for, as in many patients the calipers have to be put on before each walk and taken off afterwards, in order to prevent pressure injury. As a result, not many paraplegics actually do any such walking in their everyday life outside hospital, even where it could be useful.

The implanted femoral nerve stimulator is a neurological prosthetic aid to walking that can provide a substitute for knee calipers. Its use as an aid to walking in hemiplegia has been reported by Waters (1977) in four patients. We here report its application in two cases of complete traumatic paraplegia.

\section{Implant and Associated Apparatus}

The femoral nerve stimulator consists of an implanted part and an external part (Fig. I). Both were designed and made in the M.R.C. Neurological Prostheses Unit. The implanted part comprises electrode-pairs of platinum-iridium alloy (Io per cent iridium), each connected by a flexible cable to one of an array of five or six subcutaneously implanted passive radio receivers (circuit B of Brindley, I964). An electrode-pair consists of two parallel wires $7 \mathrm{~mm}$ apart, each wire Io $\mathrm{mm}$ long and $0.08 \mathrm{~mm}$ in diameter. Each electrode-pair is held in contact with the nerve that it simulates by a loosely fitting silicone rubber cuff that encircles the nerve. This cuff is continuous with the sheath of the cable.

The radio receivers are driven by transmitters glued to the skin over them. The block of five or six transmitters is connected by a single flexible cable to driving circuitry and batteries, contained in a pocket-sized box. The stimulator can be switched on and off by the subject as required, and is arranged so that when switched the pulse size rises or falls slowly, over an adjustable period, so that the knees straighten or relax smoothly. A switch is provided that is worn on a fingerring, so that the patient can switch his stimulator on or off whilst holding his 


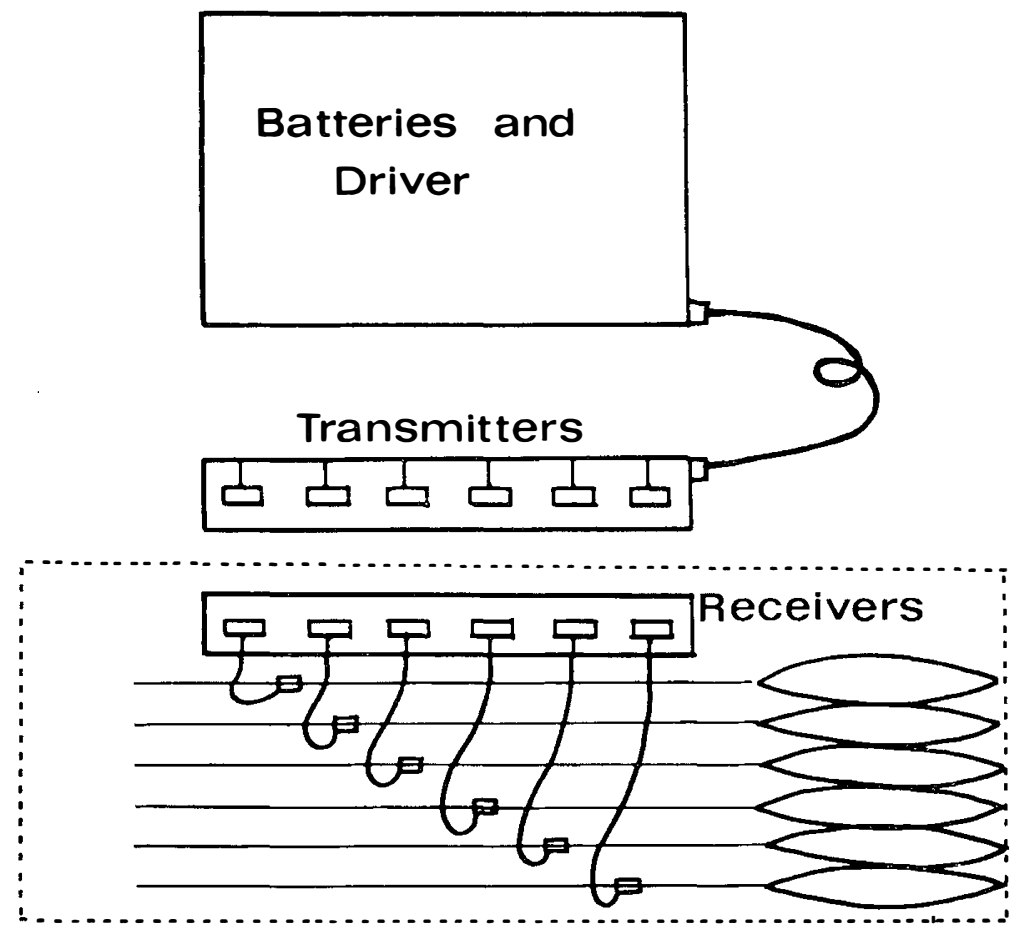

FIG. I

Schematic diagram of implant system. The patient is indicated by a dotted line. Passive radio receivers provide independent links each allowing stimulation of a nerve at a rate, strength and pulse duration determined by adjustment of the external apparatus. Each receiver contains a blocking capacitor to prevent net charge transfer, which will give a pulse decay time constant (depending on the tissue impedance) of about $\mathrm{I}-2 \mathrm{msec}$. The recovery time constant between pulses is about ro msec.

elbow crutches; this is to help him to rise or sit down safely. The power pack, transmitters, receivers and cables otherwise in general resemble those used by us for cerebellar stimulation in epilepsy (Fenton et al., 1977). The usual stimulus is a train of pulses each of $100 \mu$ sec duration, at 13 pulses/sec, but this can be varied for test purposes by replacing the portable apparatus by a Devices gated pulse generator and stimulator.

\section{Patients}

Two patients have so far received such implants. The first of these (Mr A. F., aged 38 when implanted in July 1977) has had a complete traumatic cord lesion at $\mathrm{T}_{7}$ segmented level, with preservation of reflex function below, since November 1975. His implant has five channels in all. The electrodes are on the trunks of both femoral nerves (below the branch to sartorius), both inferior gluteal nerves, and the right superior gluteal nerve.

The second patient (Mr G. L. aged 40 when implanted in November 1977) has had a complete traumatic cord lesion at TI2 segmental level, with preservation of reflex function below, since August 1975. His implant has electrodes on the separate branches of the femoral nerve to vastus medialis, intermedius and lateralis in each leg (six channels in all). Rectus femoris was avoided because of its hip 
flexor action. The radio receivers are implanted just beneath the superficial fascia over the lower right ribs and costal cartilages. This proved to be a more convenient site than the right iliac fossa, which was used for $\mathrm{Mr} \mathrm{A}$. F.

\section{Muscle Fatigue}

In order to stabilise the knee in full extension, the quadriceps femoris muscle (or part of it) has to be stimulated continuously. The quadriceps femoris muscles of these patients when untrained fatigued quickly under continuous stimulation, so in early tests standing was limited to a few minutes by muscle fatigue. One way to reduce muscle fatigue is to use the lowest stimulation pulse rate compatible with a nearly-fused contraction. Although the initial tension achieved is then lower, it is still ample for standing and walking. Fig. 2 compares the initial force (i.e. the greatest force within the first $5 \mathrm{sec}$ ) at different frequencies for $\mathrm{Mr} \mathrm{A}$. F. before training. Figure 3 shows the rate of fatigue at two different frequencies. Full recovery from thorough fatigue takes more than 2 hours, so that only one fatiguing run can be done in any one session.

Another approach to the problem of muscle fatigue was to rest the different components of the quadriceps muscle in turn, and this is why in Mr G. L. the electrodes were placed on three branches of each femoral nerve. We hoped that if each of the three muscles was rested in turn for one third of the time, progressive muscle fatigue might be greatly diminished. However, this did not prove to be the case; we found that fatigue was almost fully cumulative between successive cycles of 2 min stimulation and $\mathrm{I}$ min rest, or 4 min stimulation and 2 min rest.

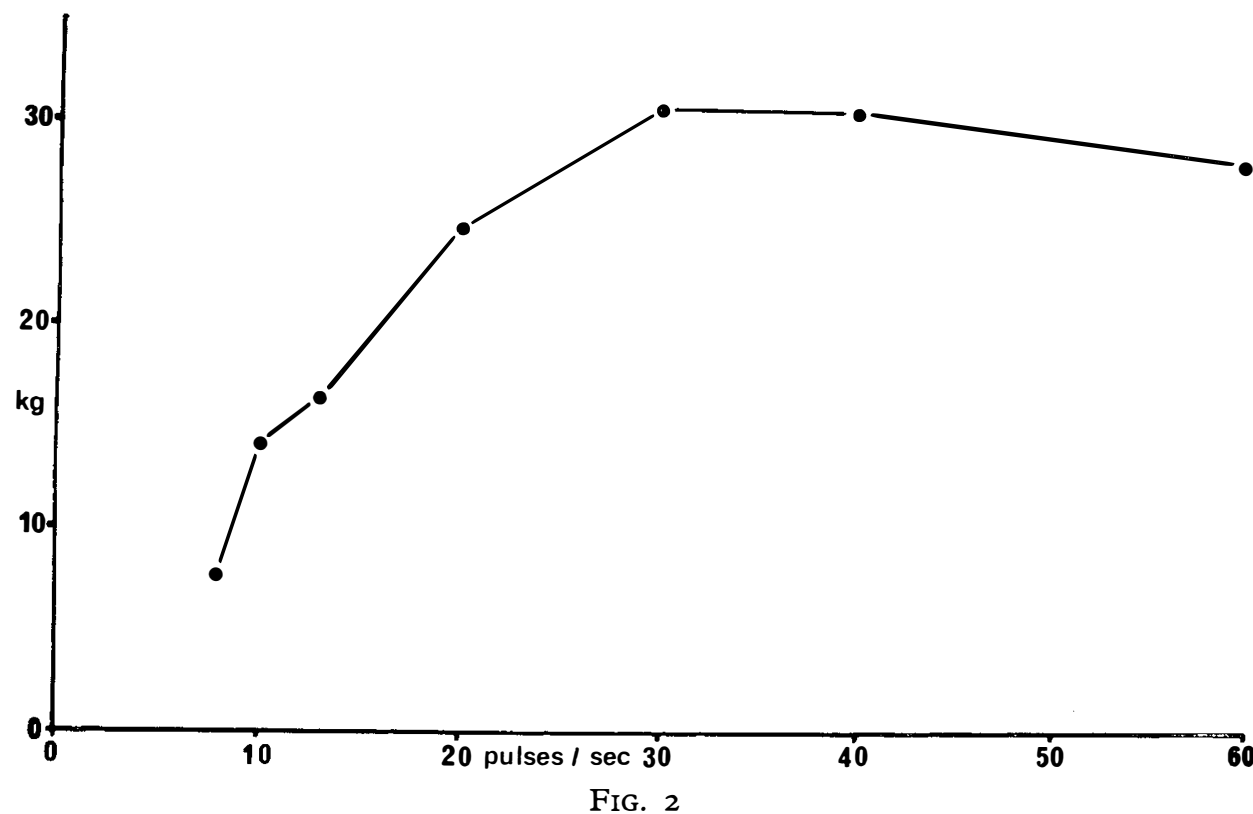

Initial force exerted by the untrained right quadriceps muscle at different frequencies of stimulation. The muscle was stimulated for not more than $5 \mathrm{sec}$ at each frequency. Subject $\mathrm{Mr} \mathrm{A}$. F. For this and the following figures force was measured at the ankle with the knee flexed to $90^{\circ}$ and the subject sitting or reclining. In early experiments (Figs. 2 and 3) the measurements were made with a spring balance, and in later experiments (most of the points of Figs. 4 and 5) with a strain gauge. 


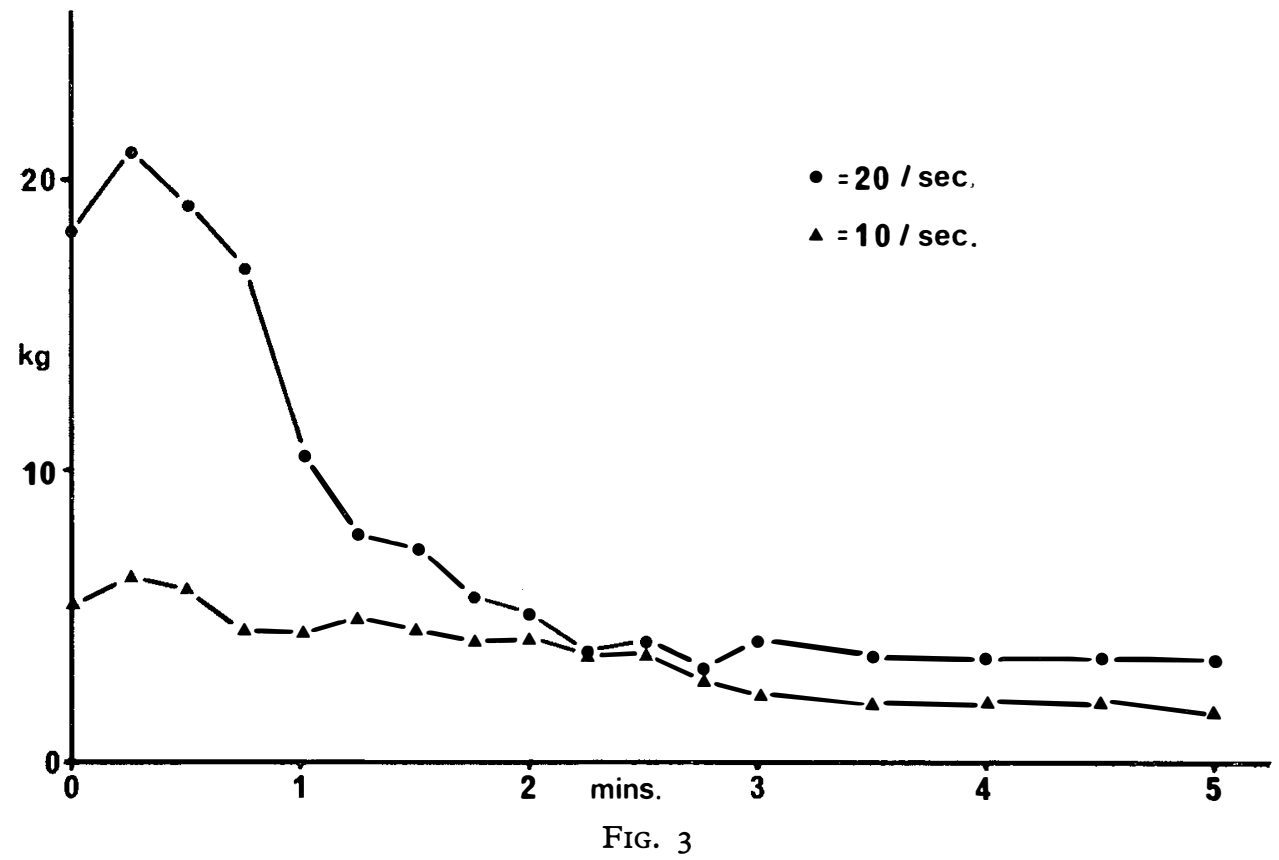

Rate of muscle fatigue in the untrained right quadriceps, with stimulation at $10 / \mathrm{sec}$ and 20/sec. Experiments were done on different days. Subject Mr A. F.

\section{Training to Increase Fatigue Resistance}

Fatigue resistance, then, needed to be improved by training. The initial force exerted by the untrained quadriceps was easily adequate for standing and walking, but it fatigued far too rapidly.

In order to increase the fatigue resistance of their muscles, both patients have used an electrical training programme, stimulating the femoral nerves maximally for 20-30 min 3-4 times daily at II pulses/sec. This low frequency and long duration of continuous stimulation was chosen partly on the general commonsense ground that it resembled that which would be used for standing and walking, and partly on the more academic ground that it resembled the procedure by which Peckham et al. (1973) succeeded in facilitating the conversion of fast fatigue-prone (glycolytic) muscle fibres to slow, fatigue-resistant (oxidative) muscle fibres in the cat.

A 30-min training session of this sort is sufficient to induce moderate breathlessness, especially in $\mathrm{Mr} \mathrm{A}$. F., who with his higher lesion has less intercostal and no abdominal muscle function.

Figure 4 shows fatigue curves made before and during 6 months of training by $\mathrm{Mr} \mathrm{G}$. L. The logarithm of the force is plotted against the duration of stimulation, because the plot (apart from the first $2 \mathrm{~min}$ ) is then roughly linear, and the slope of the regression line gives a useful index of fatiguability. It is seen that both the initial force and the force after I 5 minutes' fatigue have continued to increase in this patient for more than 4 months.

Figure 5 shows observations on fatigue before training and after different lengths of training for $\mathrm{Mr} \mathrm{A}$. F. It can be seen that here the initial force achieved changes relatively little. The fatigue resistance is increased greatly by 2 months 
of regular training, but is relatively static thereafter. After Mr A. F. had trained for $5 \frac{1}{2}$ months, training was discontinued for 2 months, and testing at the end of that time (curve 6 of Fig. 5) showed that the 2 month gap in training did not substantially reverse the increased fatigue resistance that had been built up. After that, training was restarted.

The standing endurance of both patients has increased concomitantly; whereas before training each could stand for only a few minutes, after 4 months' training Mr A. F. could stand for 35 min or walk for $15 \mathrm{~min}$. Mr G. L. after 4 months training could stand for $75 \mathrm{~min}$ or walk for $5 \mathrm{~min}$.

\section{The Gluteal Nerves}

In $\mathrm{Mr} \mathrm{A}$. F. stimulation of the right superior gluteal nerve causes abduction of the right thigh, and stimulation of either inferior gluteal nerve causes extension

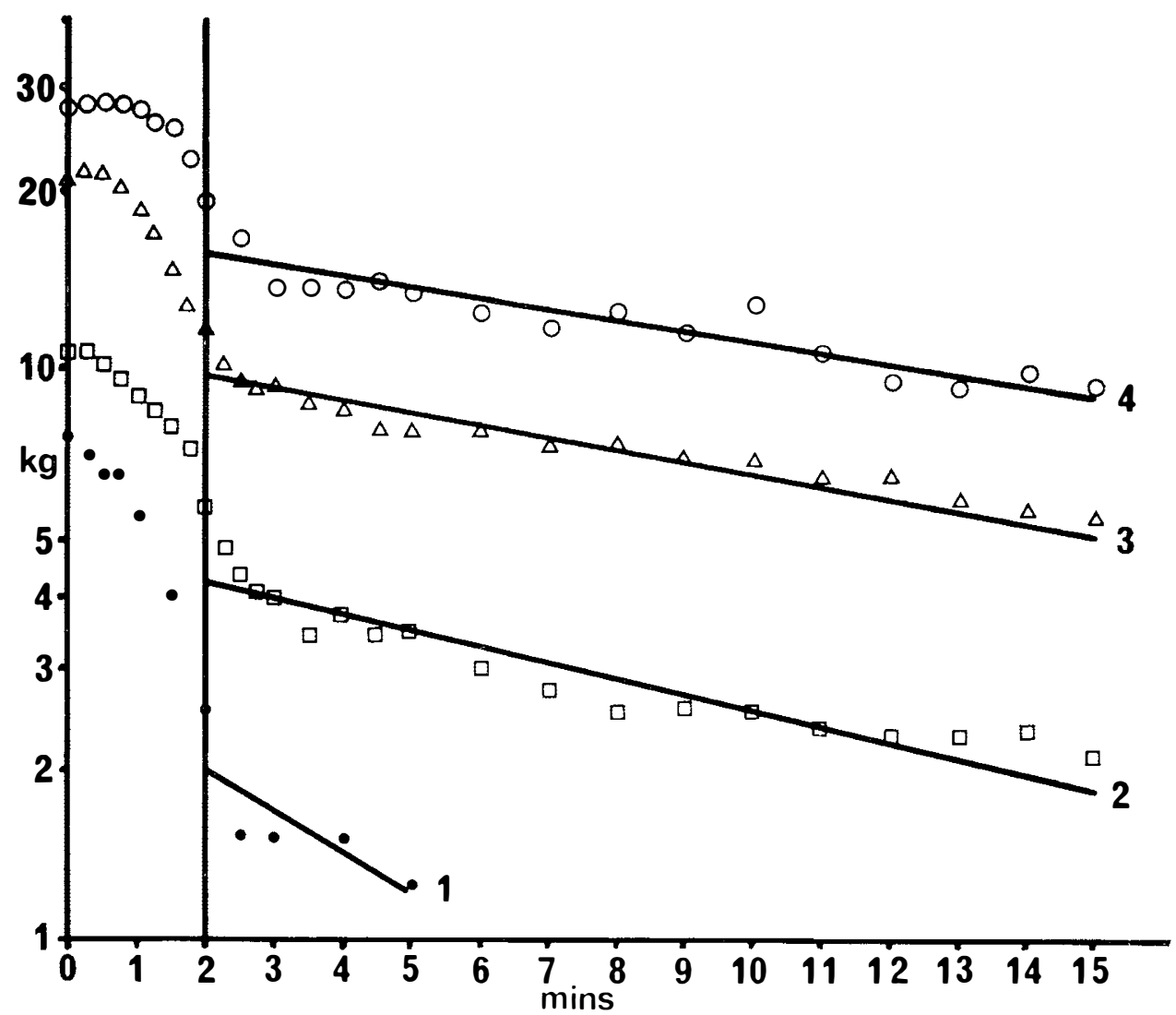

Fig. 4

Effect of training on the force exerted by the right quadriceps muscle throughout $15 \mathrm{~min}$ of stimulation at Io pulses/sec in Mr G. L. The force is plotted on a logarithmic scale against time for each fatigue experiment, and log force, after the first $2 \mathrm{~min}$, falls roughly linearly. The calculated regression line (neglecting the points for the first $2 \mathrm{~min}$ ) is superimposed on the points. The slope of the regression line gives an index of fatigue resistance. The amount of training and the correlation of the observations with their regression lines is: ( $\mathrm{I}$ ) no training, $\mathrm{r}=0.775$; (2) 8 weeks' training, $\mathrm{r}=0.927$; (3) $\mathrm{I} 6$ weeks' training, $\mathrm{r}=0.958$; and (4) 30 weeks' training, $\mathrm{r}=0.90 \mathrm{I}$. 
of the appropriate thigh. The extensor actions from inferior gluteal stimulation are a good deal weaker than we expected. The unfatigued extensor torque at the hip has never exceeded one-tenth of the unfatigued extensor torque exerted at the knee by the quadriceps at the same frequency of stimulation and degree of training. The use of gluteal stimulation does not suffice to prevent the interruption of walking by episodes of hip flexion, though it diminishes their frequency and severity.

\section{Practical Use of the Implant}

Both patients, before their operations, had learned to walk with calipers and crutches; Mr A. F. swinging or dragging his feet in each step up to the line joining the crutch tips, Mr G. L. either doing this or (in spacious surroundings) swinging them through and far beyond the crutches. Both have learned to achieve without calipers, by using their implants, a walking that is similar to their caliper walking but less confident and less secure.

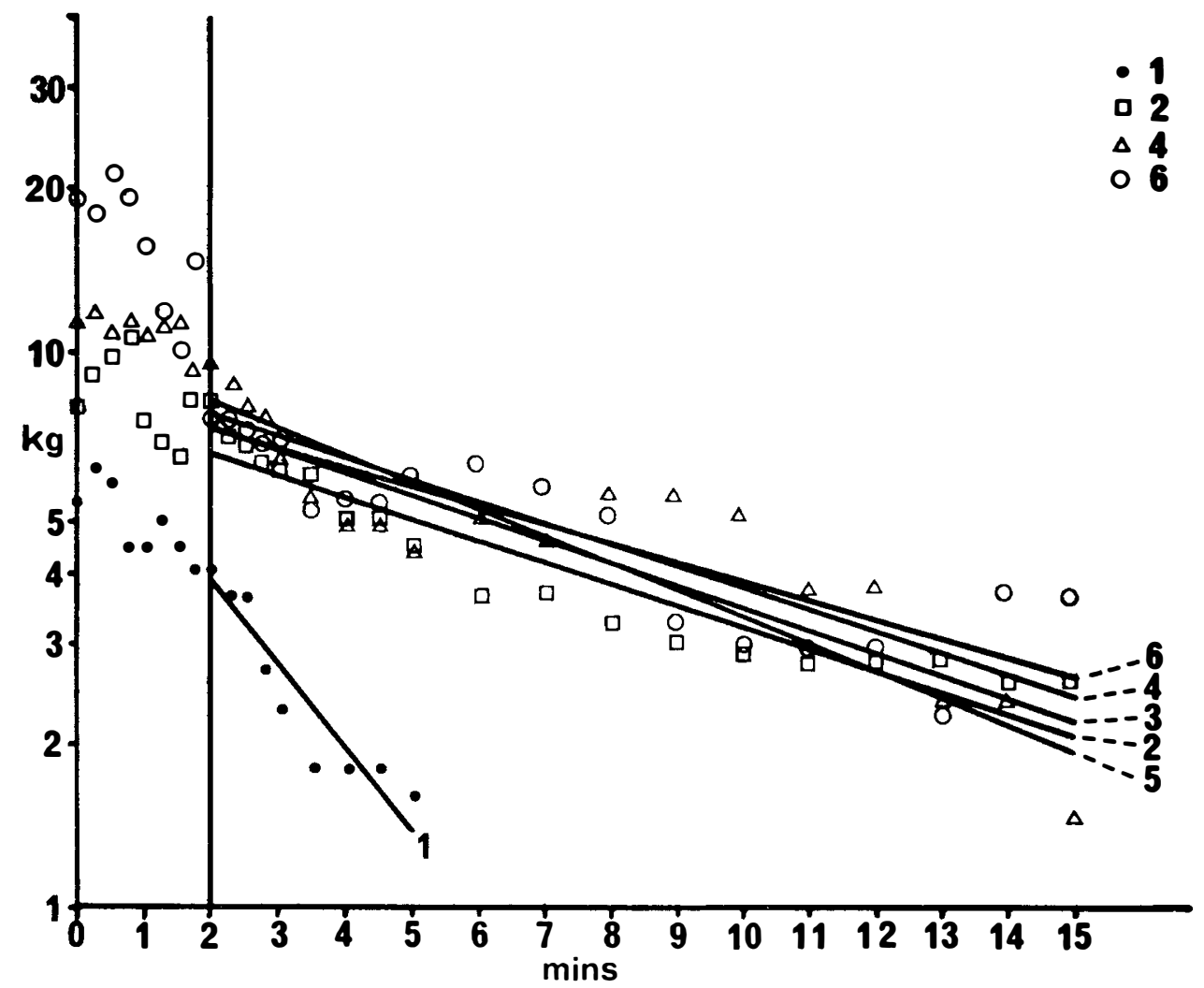

FIG. 5

Effect of training on the force exerted by the right quadriceps muscle throughout $15 \mathrm{~min}$ of stimulation at Io pulses/sec in Mr A. F., measured on six occassions before, during and after $5 \frac{1}{2}$ month's training. The points of curves $2-6$ overlap so greatly that for curves 3 and 5 only the calculated regression lines are shown in this figure. For both subjects, results for the left leg were similar to the right: (I) no training, $r=0.935 ;$ (2) 9 weeks' training, $r=0.942$; (3) I5 weeks' training, $r=0.892$; (4) $2 \mathrm{I}$ weeks' training, $\mathrm{r}=0.902$; (5) 23 weeks' training, 3 weeks' rest, $r=0.994$; and (6) 23 weeks' training, 8 weeks' rest,

$$
\mathrm{r}=0.867 \text {. }
$$


For standing and walking, both patients use all channels of their implants. running continuously at $\mathrm{I} 3$ pulses/sec. They usually set the strength of femoral nerve stimulation slightly below that which gives maximal contraction of the quadriceps, because stronger stimulation tends to cause reflex hip flexion.

$\mathrm{Mr}$ G. L. can rise from his wheelchair without help. Mr A. F. seems near to achieving this, but has not yet done so. Both patients can safely, though clumsily, return to their chairs without help. Both patients do not like to walk unless there is a skilful or strong person standing by to help if they lose balance or catch one foot behind the other.

In each step, Mr A. F. (T7 lesion) brings his feet only to the line of the crutches, and raises them only very slightly above the ground in doing so. Mr G. L. (TI2 lesion) can swing his feet far past the line of the crutches and can take them $8 \mathrm{~cm}$ above the ground in doing so. His walking speed is therefore much greater.

\section{Discussion}

Though both patients are pleased with what we have done for them, the advantage to them, regarded objectively, is small. If they keep their transmitter blocks glued to the appropriate skin area all day (which causes little or no inconvenience) and have their crutches ready to hand, they can stand and walk at a moments' notice at any time. This was never true for either of them with calipers, because they could not wear calipers all day for fear of skin injury. However, as long as they remain reluctant, on grounds of safety, to walk without a skilful or strong person standing by, they gain nothing in independence from the implants.

We publish a report now, despite the smallness of our achievement in practical terms, because we have shown in these two patients that one difficulty that might have defeated any attempt to use the quadriceps muscles in this way, i.e. muscle fatigue, can be overcome by an acceptable training schedule. We have also shown that inferior gluteal stimulation, which might have been expected to give good extension of the hips, in fact (at least in one patient) gives insufficient extension to prevent the interruption of walking by episodes of hip flexion. We suspect that the part of the adductor magnus muscle that is innervated by the sciatic nerve may be a much more powerful extensor of the hip than the gluteus maximus. Whether it has enough adductor action to make its extensor action unusable for the purpose for which we tried the gluteus maximus cannot be decided on evidence now available.

It is difficult to test whether any of the improved fatigued-resistance that we achieved by training is due to conversion of fast (glycolytic or Type 2) fibres to slow (oxidative or Type I) fibres. The question could be answered beyond doubt only by biopsies taken before and after training, and it would be difficult to justify taking these unless there was a clear practical importance in the answer. Indirect (and not wholly compelling) evidence could be obtained by repeating after training the experiment of Fig. 2, and by measuring the time-courses of isometric twitches. We have done the first of these (it gave inconclusive result), and shall do the second.

\section{SUMMARY}

Femoral nerve stimulators for knee splinting have been implanted in two paraplegic patients, who have learned to stand and walk using them. The isometric force exerted by the quadriceps femoris muscles and the resistance of these muscles to fatigue has been greatly increased by simulating their nerves 
for 20-30 min 3-4 times daily. After 5 months of such training the improvement is not lost during two months rest.

\section{RÉSUMÉ}

Des stimulateurs des nerfs femoraux pour éclisser les genoux ont été implantés dans 2 paraplégiques qui ont appris à s'en servir pour se tenir debout et pour marcher. La force isométrique exercée par les muscles quadriceps femoris et la resistance de ces muscles à la fatigue ont été largement accrues en stimulant leurs nerfs à I I chocs par seconde pendant 20 à 30 minutes 3 à 4 fois par jour. Après 5 mois d'apprentissage, l'amélioration n'est pas perdue durant une periode de repos de deux mois.

\section{ZUSAMMENFASSUNG}

Reizelektronen sind in zwei Paraplegikern implantiert worden, die die Femoralisnerven reizen und dadurch die Kniee in streckuneln befestigen. Beide Patienten haben mit Gebrauch dieser Reizapparate zu stehen und zu gehen gelernt. Der isometrische Kraft, den die Quadricepsmuskeln anwenden, und die Fähigkeit dieser Muskeln, Ermüdung zu widerstehen, ist durch 3 bis 4 Mal tägliche Reizung während jedesmal 20 bis 30 Minuten mit I I Reizen pro Sekunde viel erhöht worden. Nach 5 Monaten socher Trainierung wird die Verbesserung während einer Pause von 2 Monaten nicht beträchtlich vermindert.

\section{REFERENCES}

BRINDLEY, G. S. (I964). Transmission of electrical stimuli along many independent channels through a fairly small area of intact skin. F. Physiol., 177, 44-46P.

Fenton, G. W., Fenwick, P. B. C., Brindley, G. S., Falconer, M. A., Polkey, C. E. \& Rushton, D. N. (1977). Chronic cerebeller stimulation in the treatment of epilepsy: a preliminary report. In J. K. PENNY (ed.), Epilepsy: the eighth international symposium, pp. 333-344. Raven Press, New York.

Peckham, P. H., Mortimer, J. T. \& Van Der Meulen (1973). Physiologic and metabolic changes in white muscle of cat following induced exercise. Brain Research, 50, 424-429.

WATERS, R. (1977). Electrical stimulation of the peroneal and femoral nerves in man. In F. T. HAMBrecht \& J. B. Reswick (eds.), Functional Electrical Stimulation: applications in neural prostheses, pp. 55-64. Marcel Dekker, New York. 